\title{
Harvest Season Artificial Bee Colony, Superior Performances on Combined Economic and Emission Dispatch of Power System
}

\author{
A. N. Afandi and Hajime Miyauchi
}

\begin{abstract}
A total operating cost of power system operation is one of the most important problem. Technically, this problem considers fuels and emissions of generating units performed in a Combined Economic and Emission Dispatch (CEED) due to a total load demand at a certain time under some constraints. This paper compares the effectiveness of various latest methods of artificial bee colony (ABC) algorithm as the newest evolutionary computation methods to determine the best solution of the CEED problem. To compute the CEED problem, the methods used programming simulations are applied to the IEEE-62 bus system. Simulation results show that the tested methods have difference values in term of characteristic, speed, starting point and statistical values. Based on performances of ABC's generations, Harvest Season Artificial Bee Colony Algorithm has better results and it seems strongly to be a new approach to solve CEED problem.
\end{abstract}

Index Terms-Bee, cost, economic, emission, power system.

\section{INTRODUCTION}

A power system is operated to deliver electric energy from generators to load areas considered the least cost strategy under operational constraints. The technical operating cost is commonly approached by using an Economic Dispatch (ED) of generating units due to a total load demand at a certain time. Recently, pollutant emissions are considered in the ED problem as an Emission Dispatch (EmD). These pollutants are produced at thermal power plants, like $\mathrm{CO}, \mathrm{CO}_{2}, \mathrm{SO}_{\mathrm{x}}$ and $\mathrm{NO}_{\mathrm{x}}$ [1]-[4]. By considering pollutant emissions, the ED problem is composed into a Combined Economic and Emission Dispatch (CEED) as single objective function for determining a committed schedule of generating unit outputs.

The CEED problem is able to solve using various techniques. Many methods have been proposed to search optimal solutions divided into traditional and evolutionary methods [5]. Traditional methods are useful and accurate for searching solutions but it suffers for large systems and multi spaces. On other hand, evolutionary methods have become alternative ways to improve performances of classical methods. These methods are composed by intelligent techniques for determining optimum results. Currently, evolutionary methods are frequently used to bring out various

Manuscript received April 9, 2013; revised June 29, 2013.

A. N. Afandi is with Computer Science and Electrical Engineering, Kumamoto University, Kumamoto-ken, 860-8555 Kumamoto-shi, 2-39-1 Kurokami, Chuo-ku, Japan and Electrical Engineering, State University of Malang, Jl. Semarang 5, Malang 65145, Jawa Timur, Indonesia (e-mail: an.afandi@ieee.org, an.afandi@ymail.com).

Hajime Miyauchi is with Computer Science and Electrical Engineering, Kumamoto University, Kumamoto-ken, 860-8555 Kumamoto-shi, 2-39-1 Kurokami, Chuo-ku, Japan (e-mail: miyauchi@cs.kumamoto-u.ac.jp). cases of optimization. The newest evolutionary method is an Artificial Bee Colony (ABC) Algorithm [6]. In 2007, the powerful of $\mathrm{ABC}$ was compared with popular algorithms of evolutionary method, like Genetic Algorithm, Particle Swarm Optimization and Particle Swarm Inspired Evolutionary Algorithm [7]. These works reported that the $\mathrm{ABC}$ had better performances for searching the solution. A couple years, many previous works have used $\mathrm{ABC}$ to solve optimization problems and many researchers have developed to further studies in many aspects for the ABC.

Inspired by dynamic search directions, an improvement of $\mathrm{ABC}$ was released in 2010 and this development was called in Smart Flight ABC (SFABC) [8]. One year later in 2011, the newest development of $\mathrm{ABC}$ was inspired by an unfeasible initial population and it is called in Smart Bees ABC (SBABC) [9]. In 2012, the modifications were inspired by several themes for searching solutions. The Multiple Onlooker ABC (MOABC) used multiple onlooker bees for finding a feasible solution in the promising search area [10]. One other is an Improved $A B C$ (IABC) inspired by a differential evolution [11]. A novel type of the $A B C$ algorithm is a Harvest Season Artificial Bee Colony (HSABC) composed by multiple food sources for attempting flowers of a harvest season area [12].

Considering various types of the $\mathrm{ABC}$ 's methods, this paper evaluates the performances of ABC's methods on the CEED problem under some operational constraints. For these purposes, IEEE-62 bus is adopted as a sample model of power system for evaluating $\mathrm{ABC}$ 's performances.

\section{Problem StATEMENT}

A problem of CEED is addressed to minimize the total fuel cost of $\mathrm{ED}$ and total emission cost of EmD in single objective function with considering several limitations for the power system [13]- [16]. Basically the ED is related to the nonlinear equation as an objective function to gets the minimum total cost. The total cost of ED can be formulated by equation (2) with a fuel cost of each generating unit is expressed by equation (1).

At present, pollutants are considered in the ED [2], [16], [17]. The pollutant discharge of generating unit is formed in expression (3) and the minimized function as an Emission Dispatch (EmD) is given by equation (4). The ED problem has become an important task in the power system operation with considering a total cost and reducing pollutant emissions. Currently, ED and EmD can be composed into a CEED with including a penalty factor and a compromised factor. Each penalty factor is performed in equation (5) to 
shows the rate coefficient of each generating unit at its maximum output for the given load [13], [15]. The compromised factor shows the contribution of ED and EmD in the computation. The CEED is expressed in equation (6) and this single objective function is able to performs using several constraints in expressions (7) - (14). In general, the dispatching problem is commonly formulated by mathematical functions as follows:

$$
\begin{gathered}
F_{i}\left(P_{i}\right)=c_{i}+b_{i} P_{i}+a_{i} P_{i}^{2}, \\
\text { ED minimize } F_{t c}=\sum_{i=1}^{\mathrm{ng}}\left(c_{i}+b_{i} \cdot P_{i}+a_{i} \cdot P_{\mathrm{i}}^{2}\right) \\
E_{i}\left(P_{i}\right)=\gamma_{i}+\beta_{i} \cdot P_{i}+\alpha_{i} \cdot P_{\mathrm{i}}^{2}, \\
\text { EmD minimize } E_{t}=\sum_{i=1}^{\mathrm{ng}}\left(\gamma_{i}+\beta_{i} \cdot P_{i}+\alpha_{i} \cdot P_{i}^{2}\right), \\
h_{i}=\frac{F_{i}\left(P_{i}^{\max }\right) / P_{i}^{\max }}{E_{i}\left(P_{i}^{\max }\right) / P_{i}^{\max }}, \\
P_{G p}=P_{D p}+V_{p} \sum_{q=1}^{\mathrm{nBus}} V_{q}\left(G_{p q} \cdot \cos \theta_{\mathrm{pq}}+B_{p q} \cdot \sin \theta_{\mathrm{pq}}\right), \\
\sum_{G p}^{\mathrm{ng}} P_{i=P_{D p}}+P_{p} \sum_{q=1}^{\mathrm{nBus}} V_{q}\left(G_{p q} \cdot \sin \theta_{\mathrm{pq}}-B_{p q} \cdot \cos \theta_{\mathrm{pq}}\right), \\
P_{L}=\sum_{p=1}^{\mathrm{ng}} \sum_{q=1}^{\mathrm{ng}} P_{p} \cdot B_{p q} \cdot P_{q}+\sum_{p=1}^{\mathrm{ng}} B_{0 p} \cdot P_{p}+B_{00}, \\
P_{i}^{\min } \leq P_{i} \leq P_{i}^{\max }, \\
Q_{i}^{\min } \leq Q_{i} \leq Q_{i}^{\max }, \\
V_{p}^{\min } \leq V_{p} \leq V_{p}^{\max }, \\
S_{p q} \leq S_{p q}^{\max },
\end{gathered}
$$

where $F_{i}$ is a fuel cost of $i^{\text {th }}$ generating unit $(\$ / \mathrm{hr}), P_{i}$ is a output power of $i^{\text {th }}$ generating unit, $a_{i}, b_{i}, c_{i}$ are fuel cost coefficients of $i^{\text {th }}$ generating unit, $F_{t c}$ is a total fuel cost, ng is number of generating unit, $E_{i}$ is an emission of $i^{\text {th }}$ generating unit $(\mathrm{kg} / \mathrm{hr}), \alpha_{i}, \beta_{i}, \gamma_{i}$ are emission coefficients of $i^{\text {th }}$ generating unit, $E_{t}$ is a total emission $(\mathrm{kg} / \mathrm{hr}), h_{i}$ is each penalty factor of $i^{\text {th }}$ generating unit, $\Phi$ is the $\operatorname{CEED}(\$ / \mathrm{hr}), w$ is a compromised factor, $h$ is a penalty factor selected from ascending order of $\mathrm{h}_{\mathrm{i}}$ for the $P_{D}, P_{D}$ is a total power load demand, $P_{L}$ is a total transmission loss, $P_{G p}$ and $Q_{G p}$ are power injections of load flow at bus $p, P_{D p}$ and $Q_{D p}$ are load demands of load flow at bus $p, P_{p}$ and $P_{q}$ are power injections at bus $p$ and $q, P_{i}^{\min }$ is a minimum output power of $i^{\text {th }}$ generating unit, $P_{i}^{\max }$ is a maximum output power of $i^{\text {th }}$ generating unit, $Q_{i}^{\max }$ and $Q_{i}^{\min }$ are maximum and minimum reactive powers of $i^{\text {th }}$ generating unit, $V_{p}{ }^{\max }$ and $V_{p}{ }^{\min }$ are maximum and minimum voltages at bus $p, V_{p}$ and $V_{q}$ are voltages at bus $p$ and $q, S_{p q}$ is a total power transfer between bus $p$ and $q, S_{p q}{ }^{\max }$ is a limit of power transfer between bus $p$ and $q$.

\section{ABC's GENERATIONS}

Various ABC's methods have been inspired by many themes. These improvements have been created from a certain inspiration to make a specific modification on the original ABC. Every type of ABC's generation has an own originality statement for each algorithm although it is consisted by employed bees, onlooker bees and scout bees.

In the $\mathrm{ABC}$, employed bees have the task for searching new neighbor food sources, onlooker bees have the task for watching the employed bee in order to know where the food sources and scout bees have the task for helping the colony to create new solutions [6]. In detail, the $\mathrm{ABC}$ is presented in references [6], [7]. Main statements of this algorithm are given in mathematical expressions as follows:

$$
\begin{gathered}
x_{i j}=x_{\text {minj }}+\operatorname{rand}(0,1) \times\left(x_{\operatorname{maxj}}-x_{\min j}\right), \\
v_{i j}=x_{i j}+\emptyset_{i j}\left(x_{i j}-x_{k j}\right), \\
f_{i t_{i}}=\left\{\begin{array}{l}
\frac{1}{1+F_{i}}, \text { for } F_{i} \geq 0 \\
1+\operatorname{abs}\left(F_{i}\right), \text { if } F_{i} \leq 0
\end{array}\right. \\
p_{i}=\frac{\mathrm{fit}_{\mathrm{i}}}{\sum_{\mathrm{n}=1}^{\mathrm{SN}_{\mathrm{fit}}}},
\end{gathered}
$$

where $x_{i j}$ is a current food, $x_{\text {minj }}$ is minimum limits of $x_{i j}, x_{\operatorname{maxj}}$ is maximum limits of $x_{i j}, \mathrm{i}$ is the $i^{\text {th }}$ solution, $j \in\{1,2,3, \ldots$, $D\}, \mathrm{D}$ is the number of variables of the problem, $v_{i j}$ is a position of solution, $\varnothing_{\mathrm{ij}}$ is a random number within $[-1,1]$, $k \in\{1,2,3, \ldots, S N\}, S N$ is the number of solutions, $x_{k j}$ is a neighbor solution of $x_{i j}$, fit $\mathrm{fi}_{\mathrm{i}}$ is the fitness of $i^{\text {th }}$ solution, $F_{i}$ is an objective function of $i^{\text {th }}$ solution, and $\mathrm{p}_{\mathrm{i}}$ is a probability of the $i^{\text {th }}$ solution of the food source.

In 2010, the ABC was improved to become a SFABC. Main aspects of this improvement are discussed clearly by using dynamic search directions in a reference [8]. The SFABC was performed more convenient to the feasible region to find better solutions. In principle, the specific modification of the SFABC is expressed by $x_{B j}$ as an infeasible solution with $B \in\{1,2,3, \ldots, S N\}$. This statement is performed by using following equation

$$
v_{i j}=x_{i j}+\emptyset_{i j}\left(x_{k j}-x_{i j}\right)+\left(1-\emptyset_{i j}\right) \cdot\left(x_{B j}-x_{i j}\right)
$$

By considering an unfeasible initial population as an inspiration, the SBABC was proposed in 2011. This new variant performed a quite satisfactory for the constrained optimization problem and it is provided in a reference [9]. Specifically, the SBABC's innovation is presented in equation (20) with $\mathrm{lb}_{\mathrm{j}}$ is low limits of solution and $u b_{j}$ is up limits of solution as follows

$$
v_{i j}=\left\{\begin{array}{l}
2 \times l b_{j}-v_{i j}, \text { if } v_{i j}<l b_{j} \\
2 \times u b_{j}-v_{i j}, \text { if } v_{i j}>u b_{j} \\
v_{i j}, \text { otherwise }
\end{array}\right.
$$

Multiple onlooker bees were used in the MOABC as an improvement for the $\mathrm{ABC}$ and it was released in 2012. This improvement was gained for performing a greater ability to find a feasible solution in the promising search area. In detail, MOABC is presented in a reference [10] with $a_{1}, a_{2}$ and $a_{3}$ are quotients of particular solution, $x_{k-1 j}$ and $x_{k+l j}$ are other neighbor solutions of $x_{i j}, R_{j}$ is randomly value within $[0,1]$ and $\mathrm{MR}$ is a modified rate. The MOABC's statement is accommodated in following equation 
$v_{i j}=\left\{\begin{array}{l}x_{i j}+a_{1} \emptyset_{i j}\left(x_{i j}-x_{k-1 j}\right)+a_{2} \emptyset_{i j}\left(x_{i j}-x_{k j}\right) \\ +a_{3} \emptyset_{i j}\left(x_{i j}-x_{k+1 j}\right), \text { if } R_{j}<M R \\ x_{i j}, \text { otherwise }\end{array}\right.$

In 2012, the IABC was also proposed as a new improvement of the original $\mathrm{ABC}$ and it was inspired by a differential evolution. This generation had effectiveness in designs and a superior performance for finding solutions. For this algorithm, the principles are illustrated in a reference [11] with consisting a main improving statement as shown in equation (22). This statement has new parameters, there are a and $b$ for mutual differences $\left(x_{a j}\right.$ and $\left.x_{b j}\right)$ of neighbor solution for $x_{i j}$ as given in following expression with a and $b \in\{1,2,3$, $\ldots, S N\}$

$$
v_{i j}=x_{a j}+\emptyset_{i j}\left(x_{i j}-x_{b j}\right) .
$$

A novel generation of the $\mathrm{ABC}$ is a HSABC introduced in 2013. The HSABC has ability to explore candidate solutions from multiple food sources in the harvest season area. This algorithm is demonstrated in a reference [12] with main improvement as shown in following equation

$$
H_{i h o}=x_{k j}+\emptyset_{i j}\left(x_{k j}-x_{f j}\right) \cdot(\text { ho }-1)
$$

where $H_{\text {iho }}$ is a harvest season food position, $x_{f j}$ is a neighbor of $x_{k j}, f \in\{1,2,3, \ldots, S N\}$, ho $\in\{2,3, \ldots, F T\}$ and $F T$ is the total number of flowers for the harvest season.

\section{SAMPLE System AND PROCEDURES}

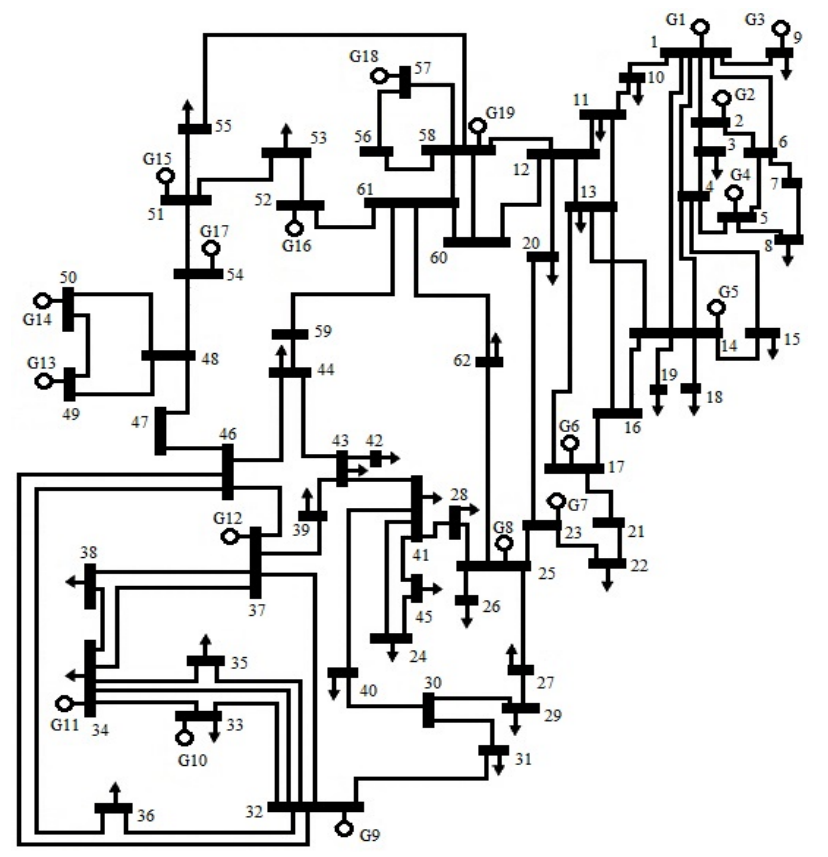

Fig. 1. One-line diagram of IEEE-62 bus system

To show the performances of various types of $\mathrm{ABC}$, the designed programs are applied to the IEEE-62 bus as a sample model of power system. This system is consisted by 19 generators, 62 buses and 89 lines. One line diagram of adopted model is shown in Fig. 1. Fuel cost and emission coefficients of generating units are listed in Table II and Table III. Load demands of the system are given in Table V.
Table I presents bee's parameters for running test the programs of the algorithms. The power limits of generators are listed in Table IV.

\begin{tabular}{clc}
\multicolumn{3}{c}{ TABLE I: BEE'S PARAMETERS FOR RUNNING TESTS } \\
\hline \hline No & Parameters & quantity \\
\hline 1 & Colony size & 100 \\
2 & Food source & 50 \\
3 & Foraging cycles & 200 \\
\hline \hline
\end{tabular}

\begin{tabular}{|c|c|c|c|c|}
\hline Bus & Gen & $\begin{array}{c}\mathrm{a}, \mathrm{x} 10^{-3} \\
\left(\$ / \mathrm{MWh}^{2}\right)\end{array}$ & $\begin{array}{c}\mathrm{b} \\
(\$ / \mathrm{MWh})\end{array}$ & $\mathrm{c}$ \\
\hline 1 & G1 & 7.00 & 6.80 & 95 \\
\hline 2 & $\mathrm{G} 2$ & 5.50 & 4.00 & 30 \\
\hline 5 & G3 & 5.50 & 4.00 & 45 \\
\hline 9 & G4 & 2.50 & 0.85 & 10 \\
\hline 14 & G5 & 6.00 & 4.60 & 20 \\
\hline 17 & G6 & 5.50 & 4.00 & 90 \\
\hline 23 & G7 & 6.50 & 4.70 & 42 \\
\hline 25 & G8 & 7.50 & 5.00 & 46 \\
\hline 32 & G9 & 8.50 & 6.00 & 55 \\
\hline 33 & G10 & 2.00 & 0.50 & 58 \\
\hline 34 & G11 & 4.50 & 1.60 & 65 \\
\hline 37 & G12 & 2.50 & 0.85 & 78 \\
\hline 49 & G13 & 5.00 & 1.80 & 75 \\
\hline 50 & G14 & 4.50 & 1.60 & 85 \\
\hline 51 & G15 & 6.50 & 4.70 & 80 \\
\hline 52 & G16 & 4.50 & 1.40 & 90 \\
\hline 54 & G17 & 2.50 & 0.85 & 10 \\
\hline 57 & G18 & 4.50 & 1.60 & 25 \\
\hline 58 & G19 & 8.00 & 5.50 & 90 \\
\hline
\end{tabular}

TABLE II: FUEL COST COEFFICIENT OF GENERATORS

TABLE III: EMISSION COEFFICIENT OF GENERATORS

\begin{tabular}{ccccc} 
Bus & Gen & $\begin{array}{c}\alpha \\
\left(\mathrm{kg} / \mathrm{MWh}^{2}\right)\end{array}$ & $\begin{array}{c}\beta \\
(\mathrm{kg} / \mathrm{MWh})\end{array}$ & $\gamma$ \\
& & & & \\
\hline 1 & $\mathrm{G} 1$ & 0.0180 & -1.8100 & 24.300 \\
2 & $\mathrm{G} 2$ & 0.0330 & -2.5000 & 27.023 \\
5 & $\mathrm{G} 3$ & 0.0330 & -2.5000 & 27.023 \\
9 & $\mathrm{G} 4$ & 0.0136 & -1.3000 & 22.070 \\
14 & $\mathrm{G} 5$ & 0.0180 & -1.8100 & 24.300 \\
17 & $\mathrm{G} 6$ & 0.0330 & -2.5000 & 27.023 \\
23 & $\mathrm{G} 7$ & 0.0126 & -1.3600 & 23.040 \\
25 & $\mathrm{G} 8$ & 0.0360 & -3.0000 & 29.030 \\
32 & $\mathrm{G} 9$ & 0.0400 & -3.2000 & 27.050 \\
33 & $\mathrm{G} 10$ & 0.0136 & -1.3000 & 22.070 \\
34 & $\mathrm{G} 11$ & 0.0139 & -1.2500 & 23.010 \\
37 & $\mathrm{G} 12$ & 0.0121 & -1.2700 & 21.090 \\
49 & $\mathrm{G} 13$ & 0.0180 & -1.8100 & 24.300 \\
50 & $\mathrm{G} 14$ & 0.0140 & -1.2000 & 23.060 \\
51 & $\mathrm{G} 15$ & 0.0360 & -3.0000 & 29.000 \\
52 & $\mathrm{G} 16$ & 0.0139 & -1.2500 & 23.010 \\
54 & $\mathrm{G} 17$ & 0.0136 & -1.3000 & 22.070 \\
57 & $\mathrm{G} 18$ & 0.0180 & -1.8100 & 24.300 \\
58 & $\mathrm{G} 19$ & 0.0400 & -3.000 & 27.010 \\
\hline \hline
\end{tabular}

Main procedures of the simulations for performing $\mathrm{ABC}$ and its generations are described by following explanations. The first step is a CEED's objective function formation as defined in Section II. This objective function is used to compute the total minimum cost of the CEED problem using each algorithm in every foraging cycle. The second step is an algorithm composition. This composition is consisted by employed bees, onlooker bees and scout bees for each type of $\mathrm{ABC}$ based on its hierarchies to search the best solution. The third step is programming developments for three categories 
subprogram considered Fig. 2 and refers to the references for the tested algorithms [6], [8]-[12].

TABLE IV: POWER LIMITS OF GENERATORS

\begin{tabular}{cccccc}
\hline \hline Bus & Gen & $\begin{array}{c}\mathrm{P}_{\min } \\
(\mathrm{MW})\end{array}$ & $\begin{array}{c}\mathrm{P}_{\max } \\
(\mathrm{MW})\end{array}$ & $\begin{array}{c}\mathrm{Q}_{\max } \\
(\mathrm{MVar})\end{array}$ & $\begin{array}{c}\mathrm{Q}_{\min } \\
(\text { MVar })\end{array}$ \\
\hline 1 & $\mathrm{G} 1$ & 50 & 300 & 0 & 450 \\
2 & $\mathrm{G} 2$ & 50 & 450 & 0 & 500 \\
5 & $\mathrm{G} 3$ & 50 & 450 & -50 & 500 \\
9 & $\mathrm{G} 4$ & 0 & 100 & 0 & 150 \\
14 & $\mathrm{G} 5$ & 50 & 300 & -50 & 300 \\
17 & $\mathrm{G} 6$ & 50 & 450 & -50 & 500 \\
23 & $\mathrm{G} 7$ & 50 & 200 & -50 & 250 \\
25 & $\mathrm{G} 8$ & 50 & 500 & -100 & 600 \\
32 & $\mathrm{G} 9$ & 0 & 600 & -100 & 550 \\
33 & $\mathrm{G} 10$ & 0 & 100 & 0 & 150 \\
34 & $\mathrm{G} 11$ & 50 & 150 & -50 & 200 \\
37 & $\mathrm{G} 12$ & 0 & 50 & 0 & 75 \\
49 & $\mathrm{G} 13$ & 50 & 300 & -50 & 300 \\
50 & $\mathrm{G} 14$ & 0 & 150 & -50 & 200 \\
51 & $\mathrm{G} 15$ & 0 & 500 & -50 & 550 \\
52 & $\mathrm{G} 16$ & 50 & 150 & -50 & 200 \\
54 & $\mathrm{G} 17$ & 0 & 100 & 0 & 150 \\
57 & $\mathrm{G} 18$ & 50 & 300 & -50 & 400 \\
58 & $\mathrm{G} 19$ & 100 & 600 & -100 & 600 \\
\hline \hline
\end{tabular}

TABLE V: LOAD DEMANDS OF THE SAMPLE SYSTEM

\begin{tabular}{cccccc}
\hline \hline Bus & MW & MVar & Bus & MW & MVar \\
\hline 1 & 0.0 & 0.0 & 32 & 0.0 & 0.0 \\
2 & 0.0 & 0.0 & 33 & 46.0 & 25.0 \\
3 & 40.0 & 10.0 & 34 & 100 & 70.0 \\
4 & 0.0 & 0.0 & 35 & 107 & 33.0 \\
5 & 0.0 & 0.0 & 36 & 20.0 & 5.0 \\
6 & 0.0 & 0.0 & 37 & 0.0 & 0.0 \\
7 & 0.0 & 0.0 & 38 & 166 & 22.0 \\
8 & 109 & 78.0 & 39 & 30.0 & 5.0 \\
9 & 66.0 & 23.0 & 40 & 25.0 & 5.0 \\
10 & 40.0 & 10.0 & 41 & 92.0 & 910 \\
11 & 161 & 93.0 & 42 & 30.0 & 25.0 \\
12 & 155 & 79.0 & 43 & 25.0 & 5.0 \\
13 & 132 & 46.0 & 44 & 109 & 17.0 \\
14 & 0.0 & 0.0 & 45 & 20.0 & 4.0 \\
15 & 155 & 63.0 & 46 & 0.0 & 0.0 \\
16 & 0.0 & 0.0 & 47 & 0.0 & 0.0 \\
17 & 0.0 & 0.0 & 48 & 0.0 & 0.0 \\
18 & 121 & 46.0 & 49 & 0.0 & 0.0 \\
19 & 130 & 70.0 & 50 & 0.0 & 0.0 \\
20 & 80.0 & 70.0 & 51 & 0.0 & 0.0 \\
21 & 0.0 & 0.0 & 52 & 0.0 & 0.0 \\
22 & 64.0 & 50.0 & 53 & 248 & 78.0 \\
23 & 0.0 & 0.0 & 54 & 0.0 & 0.0 \\
24 & 28.0 & 34.0 & 55 & 94.0 & 29.0 \\
25 & 0.0 & 0.0 & 56 & 0.0 & 0.0 \\
26 & 116 & 52.0 & 57 & 0.0 & 0.0 \\
27 & 85.0 & 35.0 & 58 & 0.0 & 0.0 \\
28 & 63.0 & 8.0 & 59 & 0.0 & 0.0 \\
29 & 0.0 & 0.0 & 60 & 0.0 & 0.0 \\
30 & 77.0 & 41.0 & 61 & 0.0 & 0.0 \\
31 & 51.0 & 25.0 & 62 & 93.0 & 23.0 \\
\hline \hline & & & & & \\
\hline
\end{tabular}

Designed subprograms of the simulations are categorized into three listing programs in terms of Data Input Program, CEED Program and Algorithm Program. The Data Input Program is consisted by a set data of parameters, for examples generating units, transmission lines, loads, constraints and parameters of CEED. The CEED Program is created to compute an objective function under operational constraints and the number of CEED's variable is associated with exploring limits of food source in the various algorithms of ABC's generation. The Algorithm Program is developed for searching the best solution of the CEED problem based on each hierarchy of ABC's generation. In this program, three types of bee are collaborated to explore food sources for choosing the best food as the solution. In the programming executions, the best food is selected by using a greedy process in every cycle.

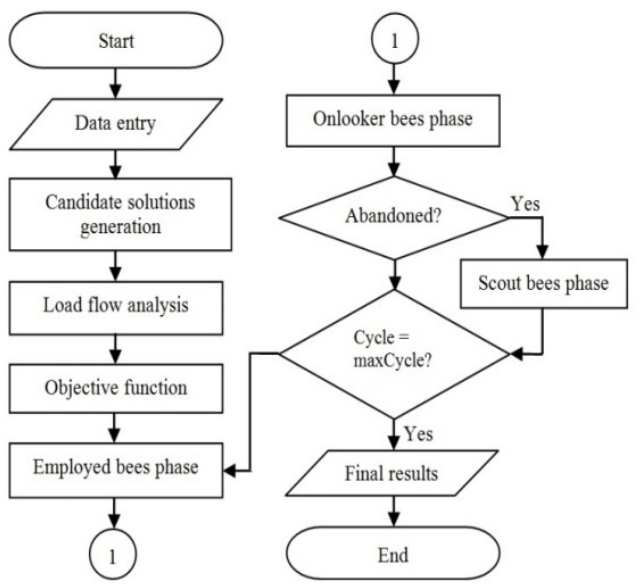

Fig. 2. Flow chart for solving CEED problem

\section{Simulation Results}

In these works, the simulations are addressed to obtain a minimum cost of CEED problem using various types of ABC. The simulations considered 2,912 MW and 1,269 MVar of total load, 0.5 of compromised factor, equality of power outputs, generating power limits, 95\% of power transfer capabilities and $\pm 5 \%$ of voltage limits as described in Section II. Designed programs for each algorithm are executed by using bee's parameters as listed in Table I. These parameters are embedded in every foraging cycle for searching the solutions. In these studies, six types of $\mathrm{ABC}$ are used to solve the CEED problem through the specific statements and computing hierarchies of its algorithm.

Refers to power constraints of generating units, a set initial population is shown in Fig. 3 as the random candidates of the foods for G1 to G19. This population is created by using maximum and minimum limits for each generating unit to locate desired solutions in the feasible ranges of the permitted power outputs. The population provides 50 candidate solutions for every foraging cycle of the algorithms and it is deployed at several positions in the population.

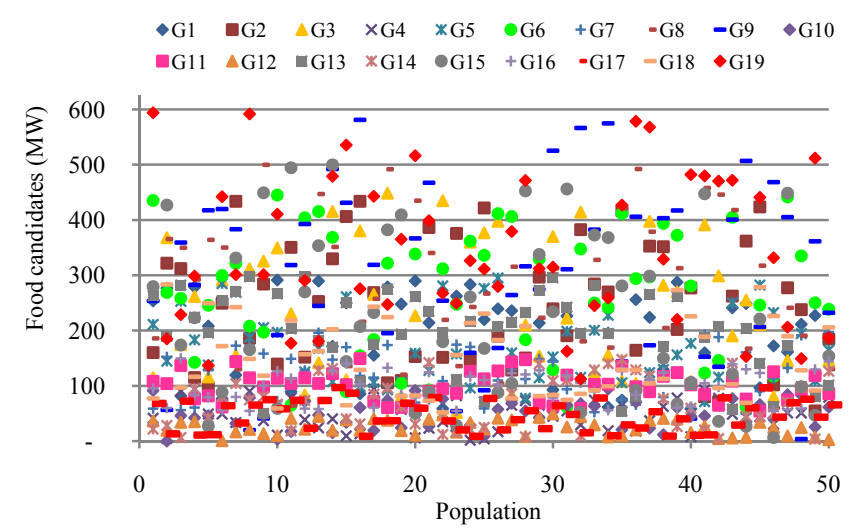

Fig. 3. Initial population for executing the ABC's generations 


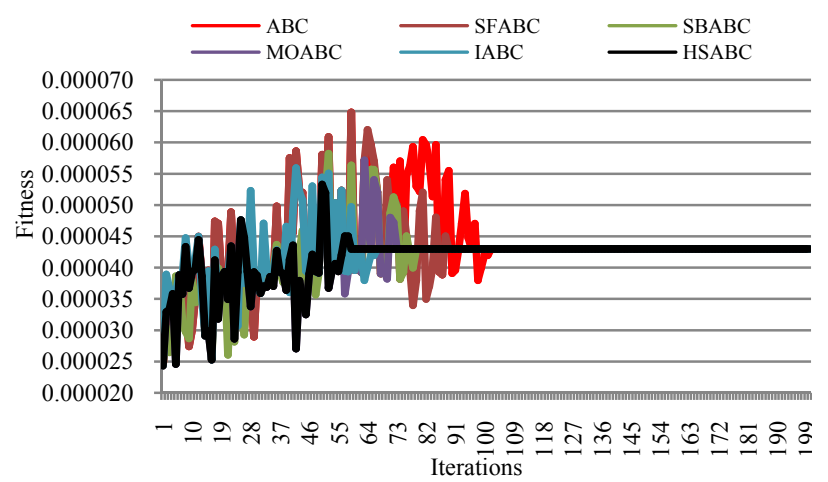

Fig. 4. Fitness of various ABC's methods

Fig. 4 shows the greedy process of each algorithm during determining the solution. This figure illustrates a food selection based on the highest fitness for searching the best solution in every cycle. By considering all parameters for the simulations, performances of the ABC's generation in the computations are expressed by CEED's results. The minimum cost result of CEED is only used for searching the best solution in the computation in all foraging cycles. This result is involved in every bee's step for determining a final solution and it is updated by a new result in every cycle for every type of ABC's method. In these studies, the minimum CEED is obtained by using 0.5 of compromised factor and its value is $14,795.51 \$ / \mathrm{hr}$. This result is contributed by $7,021.17$ $\$ / \mathrm{hr}$ of ED and 7,774.34 \$/hr of EmD. Performances of $\mathrm{ABC}$ 's methods are given in Table VI after completing the computation. This table compares results of $\mathrm{ABC}$ for the CEED problem in statistical performances. The statistical results are given in several parameters like min point, max point, range, mean, median, mode and standard deviation. From Table VI, it is known that every type of the $\mathrm{ABC}$ has difference performances. Statistically, better results are given by $\mathrm{HSABC}$ in term of start point, range, mean and standard deviation. These results show that the HSABC is more effective than other methods and it has superior performances for solving the CEED problem under operational limitations.

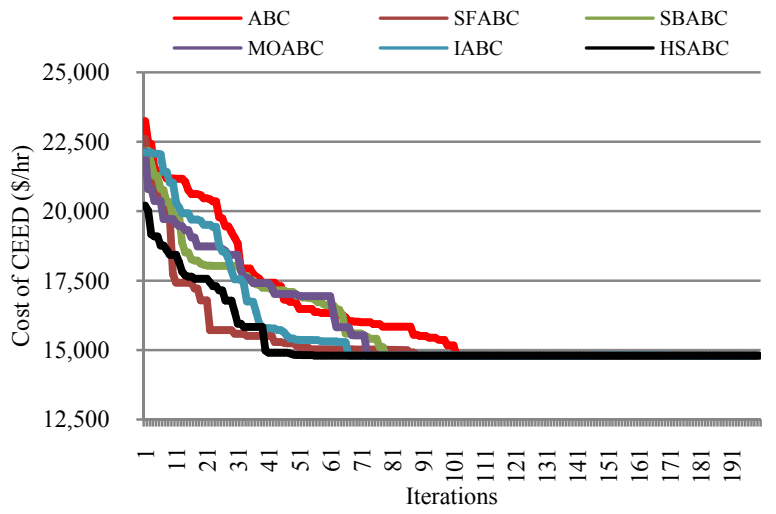

Fig. 5. CEED's convergences of various ABC's methods

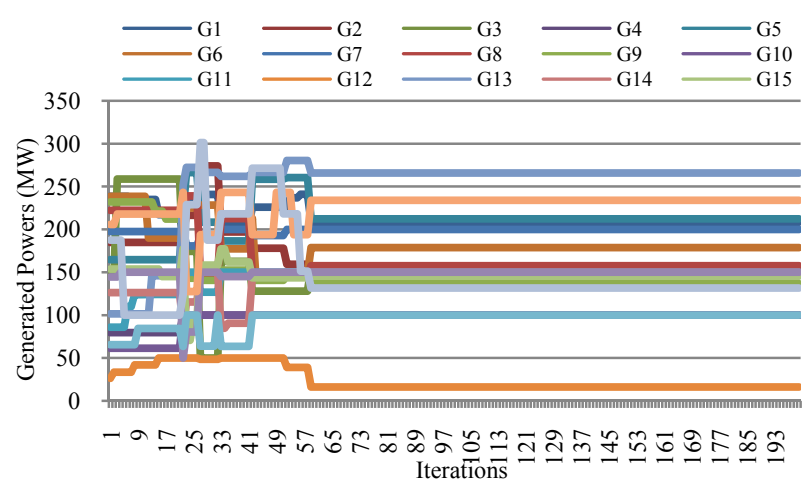

Fig. 6. Progressing powers for generating units

TABLE VI: STATISTICAL RESULTS OF CEED's COMPUTATIONS FOR THE ABC'S GENERATIONS

\begin{tabular}{lrrrrrr}
\hline \hline Subject & ABC & SFABC & SBABC & MOABC & IABC & HSABC \\
\hline Min point & $14,795.51$ & $14,795.51$ & $14,795.51$ & $14,795.51$ & $14,795.51$ & $14,795.51$ \\
Start point & $23,248.88$ & $22,614.51$ & $22,179.51$ & $22,163.51$ & $22,116.51$ & $20,205.22$ \\
Range & $8,453.37$ & $7,819.00$ & $7,384.00$ & $7,368.00$ & $7,321.00$ & $5,409.71$ \\
Mean & $16,247.15$ & $15,360.92$ & $15,902.72$ & $15,906.77$ & $15,770.14$ & $15,324.09$ \\
Median & $15,162.11$ & $14,795.51$ & $14,795.51$ & $14,795.51$ & $14,795.51$ & $14,795.51$ \\
Mode & $14,795.51$ & $14,795.51$ & $14,795.51$ & $14,795.51$ & $14,795.51$ & $14,795.51$ \\
Standard deviation & $2,132.22$ & $1,354.25$ & $1,739.42$ & $1,734.04$ & $1,955.93$ & $1,188.53$ \\
\hline \hline
\end{tabular}

Graphically, progressing computations of the ABC's methods are presented in Fig. 5. This figure shows the convergence speeds of the various ABC's generations. This figure also illustrates each characteristic of the computing ability for determining the solution of the CEED problem considered $\mathrm{ED}$ and EmD. According to Fig. 5, six various types of the ABC have different characteristics. Specifically, HSABC demonstrates the fastest computation speed for obtaining a minimum value of the CEED problem as the economic cost of power system operation. In general, the convergence speeds of the ABC's generations are 102 of $\mathrm{ABC}, 89$ of SFABC, 79 of SBABC, 73 of MOABC, 67 of IABC, and 59 of HSABC. Contrasted to the original ABC, computing speeds are improved in $12.75 \%$ by using SFABC, $22.55 \%$ by using $\mathrm{SBABC}, 28.43 \%$ by using MOABC, $34.31 \%$ by using IABC and $42.16 \%$ by using HSABC.

According to Table VI and Fig. 5, it is known that the $\mathrm{HSABC}$ has a superior for performing better results to solve the CEED problem. Concerning in 200 cycles of the foraging for the foods, the progressing power outputs of generating units for the HSABC are illustrated in Fig. 6. This figure presents the changing power of each generating unit during determining scheduled power outputs based on the minimum total cost to meet a total load. From the starting point of iteration, it is known that some generating units of power system are decreased for the power outputs, such as G1, G2, G6, G8, G9, G12, G15 and G19. One others are moved up for the produced power outputs.

Final results for scheduling 19 generating units of power system are listed in Table VII. This table shows the real condition of each power station for the committed power output considering 2,912 MW of total load. These results also inform various payments for producing power outputs. According to this table, generating units are operated in various amounts of power for supporting the power system to serve the load demand. Generating units of IEEE-62 bus 
system provide the power output in total 2,947.10 MW for supplying 2,912 MW of total load including 35.10 MW of total loss. Based on the combination of power station for the economic operation considered a minimum total cost, some generating units are operated in maximum power limits, those are G4, G7, G10, G11, G14, G16 and G17. In the committed power output, G12 is scheduled in the lowest capacity of power output and higher powers are contributed by $\mathrm{G} 13$ and $\mathrm{G} 18$.

\begin{tabular}{|c|c|c|c|c|}
\hline $\begin{array}{l}\begin{array}{l}\text { Subject } \\
\text { (MW) }\end{array}\end{array}$ & $\begin{array}{l}\text { Power } \\
(\mathrm{MW})\end{array}$ & $\begin{array}{r}\text { Fuel cost } \\
(\$ / h r)\end{array}$ & $\begin{array}{r}\text { Emis. Cost } \\
(\$ / \mathrm{hr})\end{array}$ & $\begin{array}{r}\text { Tot. cost } \\
(\$ / h r)\end{array}$ \\
\hline G1 & 208.30 & $1,815.16$ & $1,100.76$ & $2,915.92$ \\
\hline $\mathrm{G} 2$ & 154.80 & 781.00 & $1,107.25$ & $1,888.25$ \\
\hline G3 & 155.80 & 801.71 & $1,127.17$ & $1,928.88$ \\
\hline G4 & 100.00 & 120.00 & 72.15 & 192.15 \\
\hline G5 & 212.20 & $1,266.29$ & $1,158.48$ & $2,424.77$ \\
\hline G6 & 178.80 & 981.03 & $1,632.11$ & $2,613.14$ \\
\hline G7 & 200.00 & $1,242.00$ & 655.50 & $1,897.50$ \\
\hline G8 & 157.70 & $1,021.02$ & $1,159.74$ & $2,180.76$ \\
\hline G9 & 136.80 & $1,034.87$ & 868.37 & $1,903.24$ \\
\hline G10 & 100.00 & 128.00 & 72.15 & 200.15 \\
\hline G11 & 150.00 & 406.25 & 381.06 & 787.31 \\
\hline G12 & 16.00 & 92.24 & 9.94 & 102.18 \\
\hline G13 & 265.80 & 906.69 & $2,094.44$ & $3,001.13$ \\
\hline G14 & 150.00 & 426.25 & 406.25 & 832.50 \\
\hline G15 & 145.40 & 900.80 & 909.55 & $1,810.35$ \\
\hline G16 & 150.00 & 401.25 & 381.06 & 782.31 \\
\hline G17 & 100.00 & 120.00 & 72.15 & 192.15 \\
\hline G18 & 233.90 & 645.43 & $1,505.38$ & $2,150.81$ \\
\hline G19 & 131.60 & 952.35 & 835.19 & $1,787.54$ \\
\hline Total & $2,947.10$ & $14,042.34$ & $15,548.70$ & $29,591.04$ \\
\hline
\end{tabular}

As the real result of the generating unit commitment on a minimum total cost, each scheduled power output has difference implications on the individual cost of the ED and EmD. By comparing with fuel costs, higher financial supports of pollutant discharges are belonged in G2, G3, G6, G8, G13, G15 and G18. As the operational compensation, the highest emission cost is paid by G13. For the power production, G1 has the highest cost for the fuel consumption on the scheduled power of generating unit commitment. In general, the minimum total cost of the sample system is obtained in $29,591.04 \$ / \mathrm{hr}$ for providing a total power to serve the load demand. This economic payment is donated by $14,042.34 \$ / \mathrm{hr}$ of total fuel cost and $15,548.70 \$ / \mathrm{hr}$ of total emission cost.

\section{CONCLUSIONS}

This paper presents a comparison of ABC's generations for solving a CEED problem using IEEE-62 bus as a sample system. The simulations considered equality and inequality constraints as the operational limitations. The results show that all of ABC's generations have different characteristics and performances. The convergence speeds are smooth to select the solutions. Each method of the ABC's generation has ability to reduce the time consumption expressed in the obtained iteration for searching a minimum cost of the CEED problem. From six types of the $\mathrm{ABC}$, the superior algorithm is the HSABC. This algorithm has produced better results for the CEED problem. Based on the solution quality and the computational efficiency, HSABC seems strongly to be a new promising approach for solving CEED problem under several operational constraints. In these works, the simulations have used a standard model of IEEE- 62 bus system, thus applications of HSABC to real power systems are devoted to the future investigations.

\section{ACKNOWLEDGMENT}

The authors gratefully acknowledge the support and special thanks to Kumamoto University (Japan) and the BLN DIKTI (Indonesia).

\section{REFERENCES}

[1] Y. Z. Cheng, W. P. Xiao, W. J. Lee, and M. Yang, "A new approach for emissions and security constrained economic dispatch," in Proc. NAPS IEEE Conference, 2009, pp. 1-5.

[2] R. Gopalakrishnan and A. Krishnan, "A novel combined economic and emission dispatch problem solving technique using non-dominated ranked genetic algorithm," European Journal of Scientific Research, vol. 64, pp. 141-151, Nov. 2011.

[3] M. Garg and S. Kumar, "A survey on environmental economic load dispatch using lagrange multiplier method," International Journal of Electronics \& Communication Technology, vol. 3, pp. 43-46, Jan. 2012.

[4] B. H. Chowdhury and S. Rahman, "A review of recent advances in economic dispatch," IEEE Trans. On Power Systems, vol. 5, pp. 1248-1259, Nov. 1990.

[5] S. Subramanian and S. Ganesa, "A simplified approach for ED with piecewise quadratic cost functions," International Journal of Computer and Electrical Engineering, vol. 2, pp. 793-798, Oct. 2010

[6] D. Karaboga, "An idea based on honey bee swarm for numerical optimization," Technical Report-TR06, Erciyes University, Turkey, Oct. 2005.

[7] D. Karaboga and B. Basturk, "A powerful and efficient algorithm for numerical function optimization $\mathrm{ABC}$ algorithm," J. of Global Optimization, vol. 9, pp. 459-471, Apr. 2007.

[8] E. M. Montes, "Mauricio Damian Araoz, Omar Centina Dominges, "Smart Flight and Dynamic Tolerances in the Artificial Bee Colony for Constrained Optimization," in Proc. IEEE Congress on Evolutionary Computation CEC, 2010, pp. 1-8.

[9] N. Stanarevic, M. Tuba, and N. Bacanin, "Modified Artificial Bee Colony Algorithm for Constrained Problems Optimization," International Journal of Mathematical Models and Methods in Applied Science, vol. 5, pp. 644-651, 2011.

[10] M. Subotic, "Artificial Bee Colony Algorithm with Multiple Onlookers for Constrained optimization Problems," in Proc. ECC XI, European Computing Conference, 2011, pp. 242-652.

[11] X. T. Li, X. W. Zhao, J. N. Wang, and M. H. Yin, "Improved Artificial Bee Colony for Design of a Reconfigurable Antenna Array with Discrete Phase Shifters," Progress in Electromagnetics Research, vol. 25, pp. 193-208, 2012.

[12] A. N. Afandi and H. Miyauchi, "Multiple Food Sources for Composing Harvest Season Artificial Bee Colony Algorithm on Economic Dispatch Problem," in Proc. The 2013 Annual Meeting of the IEEJ, 2013, pp. 11-12.

[13] A. A. El-Keib, H. Ma, and J. L. Hart, "Environmentally Constrained ED using the Lagrangian Relaxation Method," IEEE transactions on Power Systems, vol. 9, pp. 533-534, Nov. 1994.

[14] C. C. Columbus and S. P. Simon, "A Parallel ABC for Security Constrained Economic Dispatch using Shared Memory Model," in Proc. EPSCICON IEEE Conference Publication, 2012, pp. 1-6.

[15] M. A. Abido, "Environtment/Economic Power Dispatch using Multiobjective Evolutionary Algorithms," IEEE Transactions on Power System, vol. 18, pp. 1529-1539, Nov. 2003.

[16] M. A. Abido, "Multiobjective Evolutionary Algorithms for Electric Power Dispatch Problem," IEEE Transactions on Evolutionary Computation, vol. 10, pp. 315-329, June 2006.

[17] Y. Fu, M. Shahidehpour, and Z. Y. Li, “AC Contingency Dispatch Based on Security Constrained Unit Commitment," IEEE Transactions on Power Systems, vol. 21, pp. 897-908, May 2006.

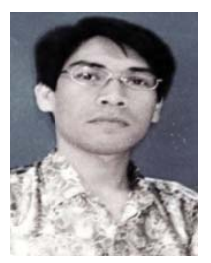

A. N. Afandi was born in Malang and he works for State University of Malang (Indonesia), since 1999. He is now with Kumamoto University (Japan) for Doctorate Program, since 2011. His research interests are in dynamic power system, economic energy operation, automatic control system and intelligent computation. He is a member of Institute of Electrical 
and Electronics Engineers (IEEE), International Association of Engineers, International Association of Engineers and Scientists, Institution of Electrical Engineers of Japan and Institute of Indonesian Engineers.

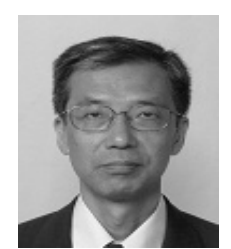

Hajime Miyauchi was born in Kyoto, Japan. He graduated from Kyoto University, Japan and hold BS, MS, and DC degrees from Kyoto University in 1981, 1983, and 1991 respectively. He joined Kyoto University from 1985 to 1993 . Then, he joins Kumamoto University, Kumamoto, Japan since 1993.

$\mathrm{He}$ is currently an Associate Professor in Kumamoto University. His research interest is on the power system control and the power system economics. He is a member of Electrical and Electronics Engineers (IEEE), and Institute of Systems, Control and Information Engineers of Japan. 